DOI https://doi.org/10.18551/rjoas.2018-04.33

\title{
ANALYSIS OF HUMAN RESOURCES STRATEGY OF PT. FOUR JAFFEE INDONESIA
}

\author{
Pusaka D.* \\ Sandikta School of Administrative Science, Indonesia \\ Susanto S. \\ Master of Management Program, Faculty of Economics and Business, \\ University of Esa Unggul, Indonesia \\ *E-mail: dantapusaka@gmail.com \\ ORCID: 0000-0002-9075-1507
}

\begin{abstract}
Business activities of PT. Four Jaffee Indonesia in achieving its objectives cause problems faced by management, not only on raw materials, work tools, production machines, money and work environment, but also related to employees / human resources who manage other factors of production. Management of professional human resources strategy will be one source from the sustainable competitive advantage from product leadership of kopita product (coffee effervescent tablet), where the human resources will continue to be motivated to give their best contribution to the growth of the company, developed their competences, and maintained so that it becomes a difficult asset imitable and not easily substituted. Some of the natural resource strategies that will be discussed in this research are: strategy, training and development of human resources, culture and corporate values, leadership, planning and fulfillment of human resources, organizational structure, type and human resources, company personnel system.
\end{abstract}

\section{KEY WORDS}

Strategy, business, human resources, development, company.

Strategies run by one company can succeed only if those strategies provide a competitive advantage over a strategy run by a competing company (David, 2011). In the analysis of business competition, some indicators can be determined whether the level of competition is high or low. The indicators used are, the number of competitors, the increasing number of competitors, the growth of similar industries in each year, the impact of industrial growth on inflation, product differentiation with competitors, raw material differentiation and production costs. In the indicator of the number of competitors, the increasing number of competitors, the growth of similar industries in each year, product differentiation with competitors and differentiation of raw materials show low competition is due to the indicator of the amount of competition, companies that produce coffee effervescent tablet in Indonesia is not there, small scale or large scale, (Lin and Saggi, 2002).

Competition in each year will be higher, it can be observed from the increasing number of companies that have product differentiation from other competitors. One of them this company has differentiation of products in the form of a unique presentation, easy and simple but still pay attention to the quality and taste. So the company can provide benefits to consumers by providing convenience and new sensation in enjoying coffee, but the product remains qualified. For raw materials, most companies have no differentiation, so competition in existing raw materials tends to be low, (Conrad, 2005)

Business activities of PT. Four Jaffee Indonesia in achieving its objectives will cause problems faced by management, not only on raw materials, work tools, production machines, money and work environment, but also related to employees / HR (human resources) who manage other factors of production. But keep in mind that human resources themselves as a factor of production, as well as other factors of production, is an input (input) processed by the company and produce an output (output). 
Management of professional HR strategy will be one source from the sustainable competitive advantage from product leadership of kopita product (coffee effervescent tablet), where the human resources will continue to be motivated to give their best contribution to the growth of the company, developed their competences, and maintained so that it becomes a difficult asset imitable and not easily substituted, (Barney, 2014). Professional human resource management should start from recruitment, selection, classification, placement according to ability, training and career development. Thus, the productivity of the company's work can be achieved and ultimately the company's performance can be improved from time to time.

McKinsey's 7s framework is a tool used to analyze the internal aspects of a company's organization using 7 key elements, Diagram 7-S illustrates the many interrelated elements that define an organization's ability to change. This theory helps the thinking about how companies can be improved with the approach of human resource management.

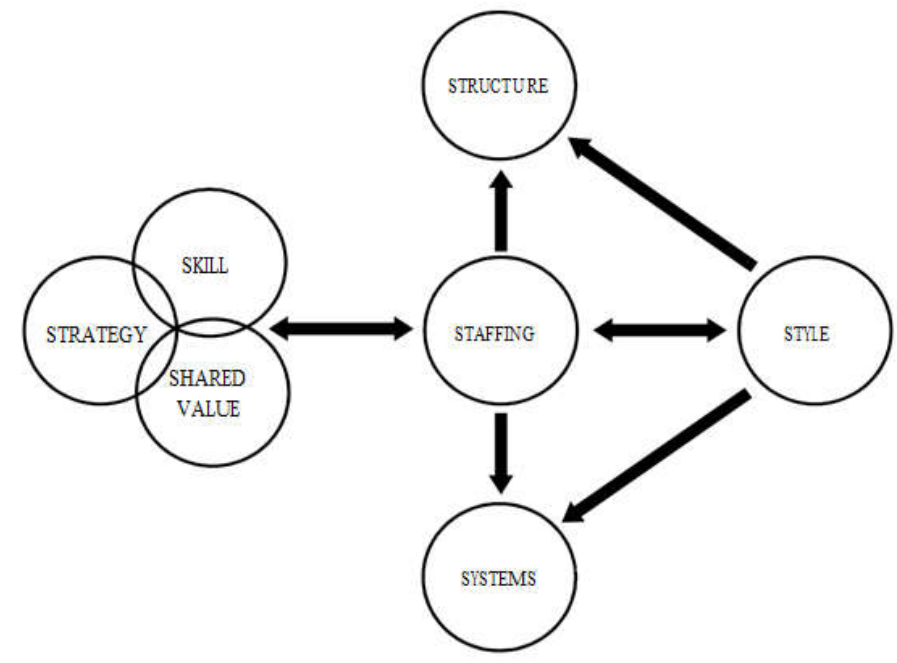

Figure 1 - Concept of Human Resource Management (Source: Peters, Waterman, Philips, 1980)

Four Jaffee Indonesia uses a business model that relies on the company's ability to produce new products as quickly as possible in the market in this case the company builds the business model of product leadership, by having excellence in product development so that has not competed yet by the competitors. Associated with generic strategy of PT.Four Jaffee Indonesia, human resource management must be able to provide employees who can create differentiation in running the program and have good knowledge in their field. In relation to the above, the objective of human resource management is to improve the productive contribution of the people or labor to the company in a way responsible strategically, ethical and social, because failure to do the task can damage the performance, productivity, profit and even the survival of the company.

Maintaining employees after being recruited and educated to have the ability expected so there will often be an offer from other companies to employees to move companies. So the company management must be able to create and grow a high sense of belonging to the company, so that employees feel part of a big family of companies. Human resource management conducted by PT. Four Jafee Indonesia refers to the company's strategy to be a product of effervescent coffee leadership in Indonesia, information needs of labor based on economic forecasting and corporate strategic plan in this case including with the plan of sale of effervescent coffee product from this information got requirement planning and then to be placed, developed with pay attention to achievement and employment appraisal as benchmark assessment and analysis.

The development and growth, characterized by an ever-increasing diversification of labor, organizational forms and global competition, the efforts of training and education allows the emplooyes to expand the duties and responsibilties. The steps taken at PT. Four 
Jaffee Indonesia in needs assessment tailored to training and development objectives. HRD prepares program and learning material that must be in accordance with the real program that can improve the skills, knowledge and ability of employees and of course this will be reevaluated as feedback on the assessment of those needs.

Development and training of human resources in the company is very closely related to the performance results of the HR Department of PT. Four Jaffee Indonesia, thus requiring an assessment to measure the performance of employees and based on the results of such assessments required in employee training. Employee training is conducted with the intention that employees have the ability, knowledge and skills in creativity in accordance with the demands of the work they are doing now, the benefits of this activity can be expanded through employee career development and assisting the development of these employees to assume the responsibility of developing the company's ability as an effervecent coffee product leadership.

PT. Four Jaffee Indonesia conducts training to its employees basically to meet the lack of knowledge and improve skills. Needs can be classified, among others, the needs of current demands, fulfilling other positions, and changing demands. PT. Four Jaffee Indonesia adjusts the type of training to be implemented and which can be developed to be effective even with the principle of learning by presentation to deliver material so as to exchange expertise or experience and encourage employees to be creative in innovation that makes the company in its strategic objectives of making effervescent coffee products as product leadership

PT. Four Jaffee Indonesia will conduct training and development in an effective and efficient manner so that the company's mission and support by the HR Department, several methods undertaken by the company include On Job Training method (OJT), cross-train method (cross-train) and method of class program (class program). The company also conducts employee planning and development as an effort to develop employees towards the right man on the right place. Companies that view excellent employee performance, experience, good education and some things related to the development of these employees.

Every corporate organization has an organizational culture that affects all aspects of the organization and the behavior of its members individually or in groups. The basic assumption patterns are found or developed by a group of people as they learn to solve problems, adapt to the external environment and integrate with the internal environment (Schein, 1995).

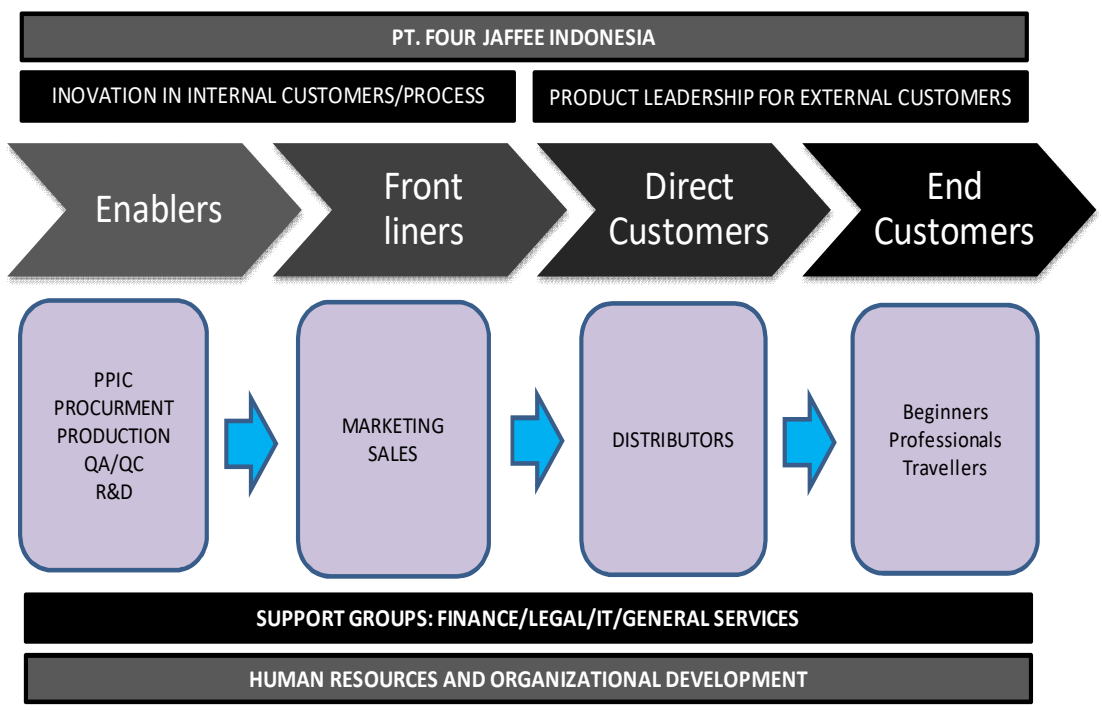

Figure 2 - Creative Flow Process \& Innovation for Customer Satisfaction PT.FJI (Source: developed for this study, 2018) 
Corporate culture is maintained because it is believed to be the answer to why the company is successful and made the company's identity. Today, the company's culture and values are engineered as a management tool to enhance the competitiveness of enterprises and compete in the global era and be able to influence the company's ability to achieve the company's competitive advantage strategy, (Kotter, 2008). Along with the development of the company, then in the end the culture and values of the company (Share Value) has become conscious beliefs and embedded in assumptions in every workers

PT. Four Jaffee Indonesia established the artifacts and values that will be grown and developed within the organization of the company as well as the basic assumptions as guidelines aimed to customer satisfaction with innovative product leadership coffee tablet.

Corporate culture is maintained because it is believed to be the answer to why the company is successful and made the company's identity. Today, the company's culture and values are engineered as a management tool to enhance the competitiveness of enterprises and compete in the global era and be able to influence the company's ability to achieve the company's competitive advantage strategy, (Kotter, 2008). Along with the development of the company, then in the end the culture and values of the company (Share Value) has become conscious beliefs and embedded in assumptions in every workers

PT. Four Jaffee Indonesia established the artifacts and values that will be grown and developed within the organization of the company as well as the basic assumptions as guidelines aimed to customer satisfaction with innovative product leadership coffee tablet.

Leadership in a company is the ability to influence all employees or subordinates to achieve corporate goals. The greatest challenge of leadership is to drive the company PT. Four Jaffee Indonesia, which continues to transform from various phases of the company's development process effectively and efficiently. So that the leader needed by PT. Four Jaffee Indonesia is a leader having transactional and transformational abilities.

Transactional leadership is concerned with the activities of a leader as a supervisor and group leader in company activities generally in short-term activities. Transformational leadership is concerned with the role that must be run by the leader as a visionary, role model and change agent. Transformational leadership is more inspiring to all employees to continue to work better in advancing the company and have a strong influence on the employees they lead (Robbins, 2003). This leadership function at PT. Four Jaffee Indonesia should be more prominent in the position of Director and Manager. While all employees of PT. Four Jaffee Indonesia will continue to build and maintain a corporate culture with the perspective of Followership Partners that employees are actively involved in every highperforming company process and promote positive relationships within the group. (Carsten et. al., 2010).

Management of human resources are activities as the implementation of the operational functions of HR management or personnel implementation such as job analysis, employee needs planning, procurement, development, integration and maintenance. In conducting this work analysis, the company evaluates the 5 dimensions of work, those are the knowledge, supervision, direction / guideline, complesity and scope. In addition to the five dimensions, it is also considered the factors of job enlargement and job enrichment for certain positions such as legal, and HR that support core staff for laboratory, operation and sales marketing.

The work plan is the development of job analysis, related to the efforts of PT. Four Jaffee Indonesia to improve efficiency, effectiveness, company productivity and employee performance. So in designing the work is strongly influenced by the technology used by PT. Four Jaffee Indonesia in every process of its work. In determining the tasks to be performed, the methods used in carrying out these tasks will be recorded in the standard Operating Procedure (SOP) and WI (work Instruction) company.

Recruitment and selection at PT. Four Jaffee Indonesia done after the results of the analysis and the design of the work has been done, then the next step is to fill positions or $\mathrm{HR}$ that match the needs of the company. The required employees can be obtained from internal and external companies. To be able to meet HR needs, HR management will process through: a) sourcing, b) selection, c) socialization. Evaluation of positions conducted 
by the company in this case is to make a systematic and regular process in determining the value of a position, relative to other positions in PT. Four Jafee Indonesia, as for one of the goals is to determine the right wage rate. Company in determining the evaluation of position using point method in the division of class and job title.

The organizational structure of the company is made based on the strategic needs of the company and the flow of business processes undertaken by PT. Four Jaffee Indonesia and the objectives of this organizational structure is to place competent employees, to continue the company policies and regulations, job delegation functions and reports and supervisory functions on the overall effectiveness of the company's business flow.

To start the company's activities, selected combinations based on mechanistic and organistic organizational structures. The mechanistic structure used in the production section requires strict control on the quality of KOPITA, so it is more vertical and refers to the applicable Standard Operating Procedure. While the organizational structure used in the sales and marketing that requires creativity and flexibility in facing customers.

Maintaining internal assumptions with creativity and implentation of innovation is by giving incentives to employees and more career ladder on employees who have succeeded, to continue to be explained in the discussion of systems and structures. PT. Four Jaffee Indonesia provides career development opportunities to employees who have the ability to creativity and high innovation after passing through multiple assessments. one of which is the success in the completion projects of the innovation that gives positive results for the company, but the seniority factor is not a benchmark in positioning within the company structure.

This system includes processes and all procedures within the company especially in human resource management activities. This procedure is used as a guideline in controlling all employees to work according to established standards and if there is an irrelevance or error as a guide for corrective action and develop the ability of employees to continue to innovate in making KOPITA as an effervescent coffee product leadership.

The general rules of employment used by the company include the provisions of working time and leaving, action on offenses and termination of employment become the foundation by HR management in managing employees. The Company determined that the normal working time for offices and factories is 5 days a week, while security, production, technical support and quality control activities are set up for 3 shifts in 1 day. At the beginning of active production is 1 shift, and the augment of the number of shifts required when the target and the need for increased sales. The following is the provision of working time in PT. Four Jaffee Indonesia.

Leave a temporary or so-called leave job, because employees sometimes take a while to not work for health reasons, family issues, education and so on. Every employees have the leaving for absence for 12 days in a year, and they only have a leaving for absence after working for 12 consecutive months. Or get advance annual leave in the following year when working 6 months.

Work discipline is a tool used by managers or leaders in PT. Four Jaffee Indonesia to communicate with employees so that they are willing to change a behavior and as an effort to raise awareness and employee's willingness to comply with all rules and norms of company. As it was known before that the company will reward every outstanding employee and warning or sanction if the employees violate the regulation and do not perform well and then it makes the detriment of the company..

There are four basic perspectives concerning work discipline, among others, retributive discipline is an attempt to punish those who do wrong, Corrective discipline is an attempt to help employees correct inappropriate behavior, the perspective of individual rights is the effort to protect induvidual rights during the course of indiscipline, a utilitarian perspective will only focus on the use of discipline only when the consequences of disciplinary action outweigh its negative effects. Here are examples of violations and their consequences

Employees commit violations in the employment relationship there is a bond between the worker and the company in the form of employment agreements, company regulations, and Collective Labor Agreements made by the company or jointly between workers / unions 
with the company, whose contents are at least the rights and obligations of each - parties and terms of employment, with agreements agreed upon by each party expected in its implementation not being breached by either party. Violations of existing agreements there must be sanctions in the form of oral or written warning, until there is also a warning letter.

Employee protection is a compensation that is not in the form of remuneration, either directly or indirectly applied by the company to employees and is an obligation that must be met, (Riley, 2005). In implementing the company's protection program, the company cooperates with insurance companies appointed by the government namely BPJS employment and BPJS Health where the two insurance companies are providing protection against possible health problems, accidents and financial problems faced by employees and their families in the future.

Employee safety and safety refers to the psychological conditions of labor resulting from the work environment provided by the company, in which case the company carries out effective safety measures that prevent employees from short or long term injuries or illnesses, as a result or risk of the work they undertake.

The role of K3 is very important for the company, because with the K3 applied in the company and it will help and facilitate the workers. Assisted with the management of the importance of OHS implementation and implementation of the field will further simplify the OHS process. Management is good, audit system that is always implemented continuously on the management of $\mathrm{K} 3$ at the factory, certainly affects the comfort and security of employees in carrying out their work, (Kai, 2011). In addition to OHS management and audits on OHS management, there are factors supporting the success of OHS, which is a complete PPE (Personal Protective Equipment) at limited liability company.

HR Department PT. Four Jaffee Indonesia with the information described above is committed to achieving the company's strategic objectives of product leadership by creating a regulatory system in accordance with the provisions of the government, creating a sense of security and stability of working comfort so as to make employees become more loyal and work harder, compensation by paying attention to the rights and employee liabilities and employee development systems that play a role in all continues improvement.

Compensation consists of two components: direct and indirect given in the hope of having a direct impact on employees, because financial compensation is a hygiene factor, which can reduce or prevent discontent. Direct financial compensation includes basic salary, holiday allowance (THR), meal allowance and transport allowance (Mehran, 1995). While indirect compensation BPJS health, BPJS Employment and other Insurance

Strategy of HR PT. Four Jaffee Indonesia one of them is to provide compensation and excellence of interest. The objective is to reward the wages of the work they have done, the rewards associated with increased sales and production capacity, rewards to the performance and competence of employees in accordance with corporate objectives, retention of employees who have competence, attitude and good achievement with indirect will attract for prospective employees in the future.

The Company maintains a safe and healthy working environment to support employees' work convenience by running a 6R corporate culture (Compact, Neat, Clean, Care, Diligent and Friendly). The company also concerns the needs of employees in terms of career security, employee welfare and learning / training opportunities so as to be able to face challenges and be responsible in completing their work, (Potter, 2003).

\section{CONCLUSION}

PT. Four Jaffee Indonesia in establishing human resource strategy refers to the company's strategy to always create product leadership in its products and one of the companies that run GMP (Good Manufacturing Practice) standard in Indonesia. With such commitment, human resources management of PT. Four Jaffee Indonesia creates a good corporate foundation for internal culture such as artifacts, company values and company assumptions from the company's internal and external. 
HR Management PT. Four Jaffee Indonesia has also prepared an activity plan for recruitment, training and development, personnel systems, corporate regulations, pursuant to Law No.13 of 2013 on Employment, KEPMEN No. 168 Year 2016 on Standard Competence Labor Industry Food Processing Basic Principles which became the basis in adjusting the company's strategy in the management of the company's workforce.

\section{REFERENCES}

1. Barney, J.B. (2014). Gaining and sustaining competitive advantage. Pearson higher ed.

2. Carsten, M.K., Uhl-Bien, M., West, B. J., Patera, J. L., \& McGregor, R. (2010). Exploring social constructions of followership: A qualitative study. The Leadership Quarterly, 21(3), 543-562.

3. Conrad, K. (2005). Price competition and product differentiation when consumers care for the environment. Environmental and Resource Economics, 31(1), 1-19.

4. David, F.R. (2011). Strategic Management Concepts and Cases. Upper Saddle River, New Jersey: Pearson Education, Inc.

5. Kai, W.U. (2011). Discussion on the establishment of incentive and restraint mechanisms for work safety standardization. Journal of Safety Science and Technology, 7(2), 164.

6. Kotter, J. P. (2008). Corporate culture and performance. Simon and Schuster.

7. Lin, P., \& Saggi, K. (2002). Product differentiation, process R\&D, and the nature of market competition. European Economic Review, 46(1), 201-211.

8. Mehran, H. (1995). Executive compensation structure, ownership, and firm performance. Journal of financial economics, 38(2), 163-184.

9. Peters, T.J., Waterman, R., and Phillips, J. R. (1980). Structure is not organization. Business Horizons, vol. 23, issue 3, 14-26.

10. Potter, E.E. (2003). Telecommuting: The future of work, corporate culture, and American society. Journal of Labor Research, 24(1), 73-84.

11. Riley, J. (2005). Employee Protection at Common Law. Federation Press.

12. Robbins, S.P. (2003). Organisational Behaviour, 10th ed., Prentice Hall, Inc.

13. Schein, Richard H. (1995). Organizational Culture and Leadership 3rd edition, JosseyBass, San Fransisco. 